\title{
Democratising Systems of Innovations based on Blockchain Platform Technologies
}

\section{Serhan Ünalan ${ }^{1}$ and Sercan Ozcan ${ }^{2}$}

${ }^{1}$ Portsmouth Business School, University of Portsmouth, University House, Winston Churchill Ave, Portsmouth PO1 2UP, United Kingdom. up877337@myport.ac.uk

${ }^{2}$ Portsmouth Business School, University of Portsmouth, University House, Winston Churchill Ave, Portsmouth PO1 2UP, United Kingdom. sercan.ozcan@ port.ac.uk

\begin{abstract}
Purpose

Blockchain is expected to have a significant impact on Systems of Innovation as the new General Purpose Technology. The purpose of this study to investigate how Blockchain can revolutionise the Systems of Innovation by investigating its overall structure, actors and relationships.

Design/methodology/approach

This study used the systematic mapping method to explore and integrate the Blockchain and Systems of Innovation literature for the creation of a new conceptual model of Blockchain-enabled Systems of Innovation. In that scope, 37 Blockchain-related and 32 Systems of Innovation-related papers, besides two major books in the field of Blockchain, have been reviewed and then integrated based on the Systems Thinking approach.

Findings

The key findings for Blockchain-enabled Systems of Innovation are that there is (1) an increased distribution of networks and collaborations, (2) increased trust through the use of reputation systems, (3) an emerging new nature of platform characteristics, (4) a democratisation of entrepreneurship by the new funding landscape and (5) an increased significance of technological drivers, such as energy.
\end{abstract}

Research limitations/implications

The study shows new Systems of Innovation-related research implications. Accordingly, a new type of actor, relationship, and attribute have been introduced where the boundaries of the role definitions are blurred and more distributed. This is where larger organisations can expect to lose their central position. The different types of actors are replaced by a network of actors as a result of the distributed new Blockchain-based system. The threshold for the Bottom of the Pyramid is expected to be reduced, leading to a more democratised innovation system.

Practical Implications

Blockchain appears to reduce the effects of distrust in collaborative innovation practices with its consensus mechanisms and the new Blockchain-enabled Systems of Innovation is expected to revolutionise the interactions in the future.

Originality/Value

There are very few studies that have been found to integrate innovation management practices with Blockchain. This is the first Blockchain-based Systems of Innovation study enabling the fundamental revision of its structure, types of relationships and actors.

Keywords - Blockchain, Systems of Innovations, Platform Technologies, Distributed Systems, Democratisation of Innovations.

\section{Introduction}

The digital revolution is expected to generate collaborative networks and a more abundant economy, i.e. the "Democratisation of Consumption" (DoC), with four main consequences on Systems of Innovation (SI) (Diamandis and Kotler, 2012; von Hippel, 2005): (1) disruptive organisations, (2) decreased barriers to innovate, i.e. "Democratisation of Innovation" (DoI), (3) emerging strategic individuals, such as Bill Gates and (4) the "Bottom of the Pyramid" (BoP), constituting the largest, and poorest proportion of the world's population (Rosling et al., 2018). DoI has the potential to transform BoP into a more viable economic force that is also recognised as a new source of radical innovation (Prahalad, 2012) with a significant influence on the SI landscape.SI is a framework of the innovation landscape which illustrates the flow of knowledge, including technology and information, among the innovation actors such as universities, private organisations, and governmental institutions. 
In that context, Blockchain, as a "trust machine", has received increasing attention by various stakeholders as a disruptive ledger technology, eliminating the need for centralised trust by revolutionising the entire SI landscape (Davidson et al., 2016).

Swan (2015) divides Blockchain into three categories, namely Blockchain 1.0, 2.0, and 3.0. Blockchain 1.0 can be considered "Internet of Money", Blockchain 2.0 is "Internet of Contracts" and Blockchain 3.0 is "Internet of Governance" or "Internet of Government". Although Blockchain is mostly aligned with cryptocurrencies, i.e. "Internet of Money", Blockchain as "Internet of Governance" is expected to be the new generation platform for collaborative, decentralised and inclusive innovations with a potential impact on our entire civilisation (Tapscott and Tapscott, 2017a). "Internet of Governance" is also expected to improve the efficacy of economic coordination so then anyone may become an entrepreneur and collaborator (Chen, 2017). Several scholars who have recognised the potential of "Internet of Governance" have started to label Blockchain as the new "General Purpose Technology" (GPT) (Davidson et al., 2016), approximating technologies such as the Internet, i.e. a key enabling technology (Wolf et al., 2014)GPTs are usually characterised by their potential for pervasive use in a wide range of sectors (Bresnahan and Trajtenberg, 1995; Lipsey et al., 2005)and by their vast impact on the SI landscape, leading to various phenomena, e.g. blurred organisational boundaries, coopetitive networks (i.e. cooperative and competitive) and different collaboration mechanisms (Davidson et al., 2016).

It appears that there is a critical need in the academic world to understand how Blockchain, in form of "Internet of Governance" may impact on the SI landscape (Warnke et al., 2016). To satisfy this critical need, a systematic literature review has been applied in order (1) to categorise the new Blockchain-enabled SI landscape from both Blockchain and SI perspectives, (2) to understand how Blockchain and SI can be fused into one SI framework, (3) to identify which kind(s) of new SI actors might be included, including their (4) relationships and (5) attributes. As there are a limited number of Blockchain-related peer-reviewed journals published in the Business \& Management domains, a systematic mapping model and the systems thinking method have been deployed in the scope of this study. This is based on 12 Blockchain-related and 32 Systems of Innovation-related papers out of 1959 papers in order to systematically review the research domain as it is otherwise lacking in relevant highquality primary studies.

This paper is structured as follows. Section 2 investigates the existing SI and Blockchain literature and highlights the key findings and positions found by this study in the academic field addressing the research gap, aim and objectives. Section 3 introduces the research method while Sections 4 and 5 cover the results, discussions, and conclusions.

\section{Literature Review}

SI serves as a valuable reference model for innovation policies, which is particularly relevant for scholars and policymakers (Markard et al., 2015), including innovation policies related to emergent technologies such as Blockchain. As an emerging multidisciplinary GPT, Blockchain is asserted to not only be confined by SI but also defined by geographic boundaries. It is also expected to influence the development of various technologies, pointing to a critical need in the academic world. Thus, this study briefly aims to investigate how Blockchain may influence the SI landscape (Warnke et al., 2016). This section outlines the various SI approaches and it also investigates how Blockchain may provide inputs for the new Blockchain-enabled SI framework by considering the most up-to-date SI studies.

\subsection{Systems of Innovation}

There are different SI models based on different boundary levels and/or components. The National Innovation System (NIS) (Lundvall, 1992) and Regional Innovation System (RIS) (Cooke et al., 1997) investigate the comparative advantages of nations and regions with regards to their innovation activities and performance. The Sectoral Innovation System (SIS) illustrates that sectors have different path dependencies in innovation interactions well beyond their spatial boundaries (Malerba, 2004). Furthermore, Carlsson and Stankiewicz (1991) introduced the Technological Innovation System (TIS), asserting that the economic growth of countries is a function of technological systems. The multi-level framework introduced by Markard and Truffer (2008) integrates different SI models focusing on the technological transitions between them.

Carlsson et al. (2002) point to the shortcomings of these models, asserting that the underlying innovation processes are much more complex than what has been depicted. The definition of the system boundaries, including the identification of actors such as in-firm actors and informal institutions (Coenen and López, 2010), stand out as the most problematic methodological issues. Binz and Truffer (2017) and Warnke et al. (2016) assert that all existing SI frameworks are missing the inclusion of a much wider range of actors, institutions and innovation modes. They need to highlight the complexity of SI's spatial configuration where there is an increasingly blurred distinction between the actors (Binz and Truffer, 2017). Klein and Sauer (2016) emphasise a need for a revised understanding. 
To address these shortcomings, the Quintuple Helix $(\mathrm{QH})$ brings in the different perspectives together in order to understand, manage and govern Mode III innovation (Carayannis and Campbell, 2010). This also fails to depict the up-to-date SI. Global Innovation Systems (GIS), which are built on existing SI approaches and that stress the transnationality of innovation (Binz and Truffer, 2017), point to the increasing interconnection of innovation activities at supranational levels. It also emphasises the distributed interaction between innovation actors, necessitating an efficient coordination mechanism. In this scope, Ozcan and Islam (2014) investigate the collaboration mechanism among the SI actors such as distributed working and information sharing. It is assumed that the key SI actors, including organisations, people, and machines, lead to clusters. Clusters lead to networks, and networks result in collaborative innovation networks (CIN) which cannot be constrained by a specific geographical area or a particular sector (Ozcan and Islam, 2014).

Thus, while SI constitutes a valuable conceptual framework for innovation policies (Markard et al., 2015), it fails to reflect the current SI landscape, which is transforming to a distributed structure with an increased need for a control mechanism at the network level. In this respect, a Blockchain-enabled SI framework is expected to address these weaknesses. The following sections will introduce Blockchain comprehensively.

\subsection{Blockchain Framework}

Blockchain combines mathematical cryptography, open-source software, computer networks and incentive mechanisms (Davidson et al., 2016). Blockchain could be seen of as the "Internet of Value", expected to eliminate powerful intermediaries to exchange things of value and by rewarding actors in the same way that email transformed sending mail by removing the need for a trusted third party such as the Post Office (Ibáñez et al., 2017).

As asserted by Ozcan and Islam (2014), the SI landscape has increasingly evolved from a centralised networkstyle to a decentralised network, enabling active collaboration between the innovation actors. In fact, collaboration between the SI actors may be linked together by different types of relationships, i.e. centralised networks, decentralised networks and distributed networks (Ozcan and Islam, 2014; Nohria, 1994), whose interactions may be influenced by various technologies, such as computer networks (Camarinha-Matos and Afsarmanesh, 2005) or Blockchain to achieve common or compactable goals in a more efficient way.

Tapscott and Tapscott (2016) explain that the pervasion of disruptive digital technologies, such as the Internet or Blockchain, paved the way for departing from the traditional culture of institutions and heading toward so-called Global Solution Networks, which are highly similar to open-source society, i.e. distributed networks of various collaborative SI actors. A Blockchain-enabled SI framework is also expected to show characteristics akin to the Internet, which is curated, orchestrated and governed by a collection of various SI actors, with less or no intervention from governments, pointing to the characteristics of "Internet of Governance".

Figure 1 illustrates how the SI landscape will be increasingly replaced by centralised and decentralised networks while particularly influencing how innovation processes are expected to be realised. Figure 1 explains as one of the bases for Figure 3, which depicts the research framework of this study.

CENTRALISED

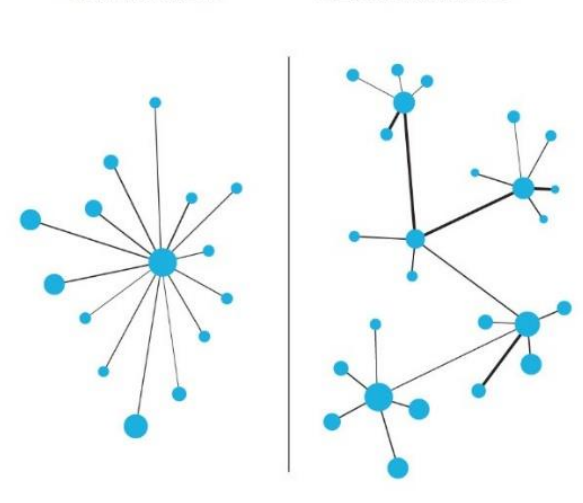

DISTRIBUTED LEDGERS

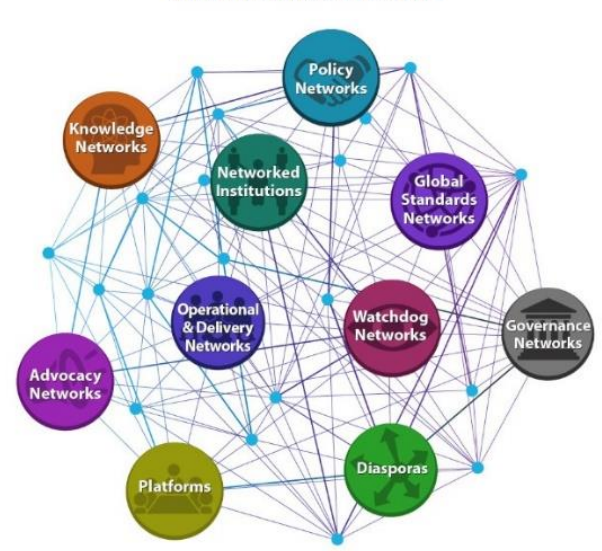

Figure 1: Own Illustration of DLT-Based Linkages - Adapted from Tapscott and Tapscott, 2016

While the Internet becomes increasingly centralised and monopolised causing network actors with different strengths to arise (Marsal-Llacuna, 2017), Blockchain is described as a democratic, universal and decentralised technology. This allows for the equal bottom-up participation of the citizen without the need for a central authority (Ibáñez et al., 2017; Marsal-Llacuna, 2017). 
“The Crypto Anarchist Manifesto" of May (1988) and “A Cypherpunk's Manifesto" of Huges (1993) describe both the competition and cooperation principles. They also define the theoretical grounds of virtual networks' coopetition. In this context, Figure 1 depicts how a new form of non-hierarchal cooperation, as a prominent example of a coopetitive virtual network, may be established between the Blockchain-enabled SI actors (Scott $e t$ al., 2017).

\subsection{Business \& Management Oriented Blockchain Studies}

Blockchain enables distributed trust and solves trust-based coordination problems, which could allow for a new form of non-hierarchal cooperation between the SI actors to emerge (see Figure 1) and replace "the traditional Hammurabi's open-source approach" to governance. This drives deep structural changes in our society, including business and management. In this respect, Blockchain offers a new way of institutional coordination for a new type of collaborative innovation networks, which is more distributed, participatory and citizen-centric which is based on transparent peer-to-peer transactions providing equal access and use to everyone (Davidson et al., 2016; Marsal-Llacuna, 2017). Although Blockchain is still new and experimental, due to the above-mentioned reasons, it is appropriately considered as a GPT and a disruptive institutional technology (Davidson et al., 2016).

As an inclusive technology, Blockchain could leverage BoP to allow for better living conditions, i.e. Financial Inclusion (Swan, 2017), which is currently excluded from existing financial systems. As demonstrated by M-Pesa in Kenya, Blockchain may democratise access to payment and investment instruments so then virtually everyone may become a potential entrepreneur and collaborator (Chen, 2017). On the other hand, Blockchain-enabled solutions could target the SDGs by (1) enabling more transparency, (2) reducing bureaucracy, (3) awarding environmentally sustainable actions with Blockchain tokens and (4) reinforcing the entitlement to use a natural resource (Sutherland et al., 2017). In that scope, Blockchain may be considered as one of the most significant enabling instruments of DoI, which tackles both scarcity and abundance. Scarcity is a market condition where demand exceeds supply, leading to the "Peak of the Pyramid" (PoP). Abundance refers to the opposite market condition, where supply exceeds demand, which leads to BoP. Whether it is PoP or BoP, there is a market failure where demand and supply are out of balance. While PoP societies face problems such as the high consumption of electricity, health-related problems associated with overeating and excessive wastage-related problems, BoP faces the opposite type of problem, such as hunger, healthcare, and low literacy levels. Thus, DoI is the only effective way to change the existing equilibrium in the market driven by disruptive innovations, i.e. Blockchain (Mahto et al., 2017), where traditional centralised institutions have failed to cope with the problems of society so far (MarsalLlacuna, 2017).

Historically trust has been assumed to be the highest in centralised and strong ledgers, such as non-corrupt and efficient government institutions. A high trust ledger creates a low transaction cost economy. This is a precondition for economic efficiency and prosperity (North, 1991; Nooteboom, 1999). However, establishing and manufacturing trust can be expensive (Davidson et al., 2016). The centralised ledgers of today face problems related to coordination in the SI landscape, which is mainly caused by the changing characteristics of SI (Binz and Truffer, 2017). Furthermore, Blockchain could enable and maintain trust efficiently while challenging the organisational theories fundamentally (Seidel, 2018). These theories include organisational ecology, institutional theory, transaction cost economics, resource dependence, and network theory, pointing to the changing assumptions and theories related to the outdated centralised institutions of today, which are assumed to be the most efficient market-based trust coordination mechanism as in the past (Yermack, 2017). It seems that Blockchain, in form of "Internet of Governance", will enable a community level governance model, i.e. Blockchain commons, which approaches the innovation process as a collective action problem resolved with governance rather than as one of a market or system failure that is resolved with governmental intervention. Thus, the economic character of the innovation problem becomes a multilateral contracting problem rather than a choice-theoretic problem of market and system failures (Potts, 2018), while the traditional SI models are challenged.SI characteristics are related to proximity with the capability to facilitate trust as well as the rapid diffusion of ideas and knowledge spill-over (Audretsch and Feldman, 1996; Nooteboom, 1999), which may be influenced by Blockchain. Furthermore, Cantù (2010) also argues that proximities drive innovation and they demonstrate that different proximity dimensions influence organisation boundaries (Lazzeretti and Capone, 2016).

Blockchain-enabled networks are assumed to be distributed and participatory environments, as demonstrated with the "Future Living" framework of Marsal-Llacuna (2017), enable coopetitive networks with the following principles: (1) virtual and physical cooperation facilitated by smart contracts,(2) a universal and decentralised network, allowing for a bottom-up participation and the contribution of citizens without a need for a central authority, including(3) collective implementation with a novel model of governance that is citizen-centric, including policies codes, planning codes and regulation codes enabled by Blockchain. In this context, Blockchain tokens, such as reputation tokens, play an important role in collaborative networks. Collaborators are rewarded for the value that they create and their effective contributions to the community are enhanced (Van Valkenburgh et al., 2015). This would also redefine entrepreneurship and innovation, particularly Open Innovation (OI). As OI 
shows limitations related to trust, Blockchain could complement the distributed nature of OI, e.g. Blockchain could serve as a security asset for identity validation and IP issues, as tokens allow for one to trace the value created by SI actors so then the interests of the OI community are provided for (Chen, 2017).

\subsection{Research Gap, Aim and Objectives}

Blockchain is claimed to be a disruptive institutional innovation with the potential to cause various phenomena of innovation, e.g. blurred organisational boundaries and different collaboration mechanisms, pointing to a critical need in the academic world to understand how Blockchain may impact on the SI landscape (Warnke et al., 2016). Furthermore, a lack of Blockchain and SI related studies is another research gap in this context, as shown in Figure 2, which illustrates the number of Blockchain-related studies found in selected scientific databases, namely Web of Science(WoS; www.webofknowledge.com) and Scopus (www.scopus.com). These consist of four different intertwined categories, starting with the most comprehensive category on top, namely Blockchain, and ending with the intersection between Blockchain and SI at the bottom.

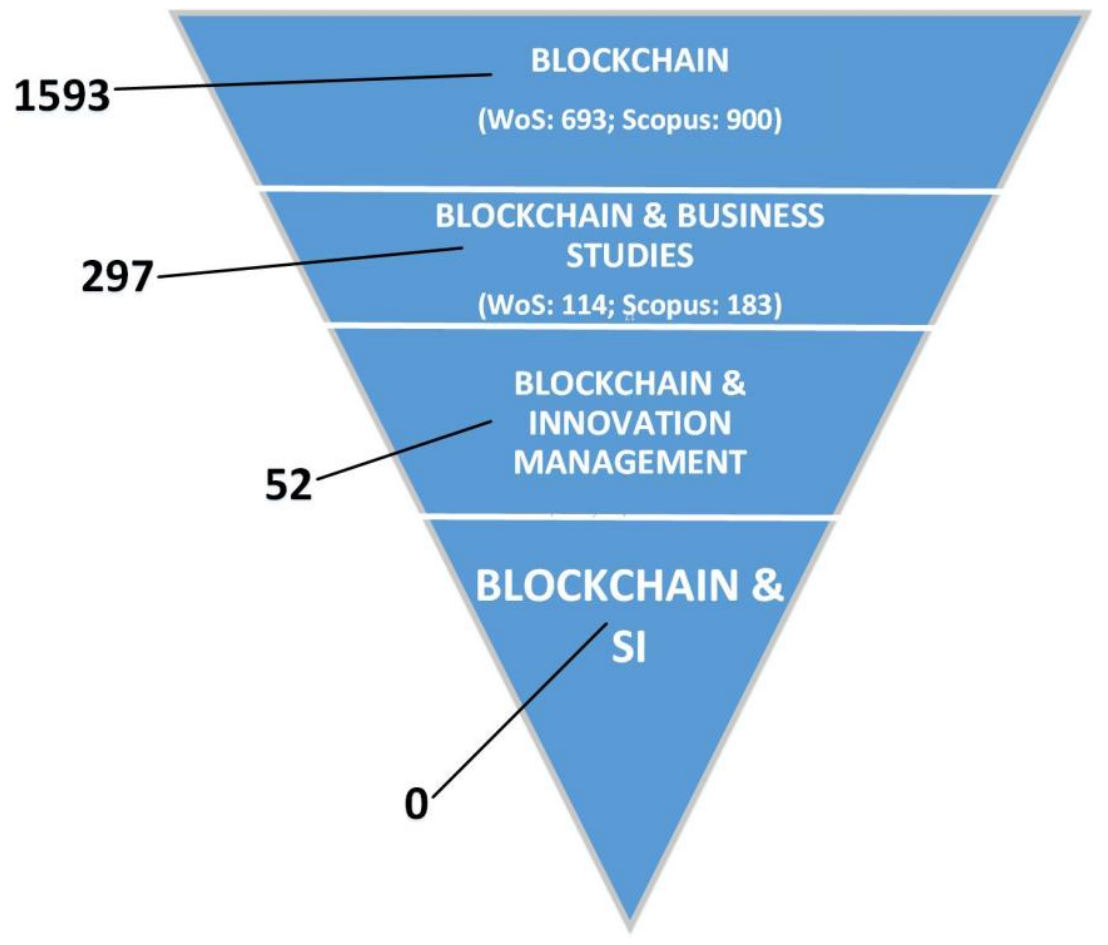

Figure 2: Number of Studies related to Blockchain

Carlsson et al. (2002) assert that several previous SI studies introduced since the Cold War show various weaknesses, including the definition of the system boundaries or the identification of actors, which stand out as the most problematic methodological issues. Ozcan and Islam (2014) claim that the collaboration between SI actors may be linked together by different types of relationships, which is strongly influenced by Blockchain technology. Furthermore, as discussed earlier in Section 2.2, SI is currently missing the wider inclusion of the SI actors which is evolving into a more distributed structure. It requires a better control mechanism at the network level, so a Blockchain-enabled SI framework has been proposed. This is expected to deal with all of the current weaknesses of SI. The proposed research framework(Figure 3) consists of two sub-frameworks, during which the upside part illustrates the most up-to-date SI framework, which is an overlap of the previous SI approaches, including GIS, NIS, RIS, SIS, TIS, the multi-level framework and the Quintuple Helix, without the influence of Blockchain technology. The under part illustrates the proposed Blockchain-enabled SI framework while also reflecting the most up-to-date SI framework. This is influenced by Blockchain technology, so the SI actors show distributed characteristics along with blurred boundaries. 


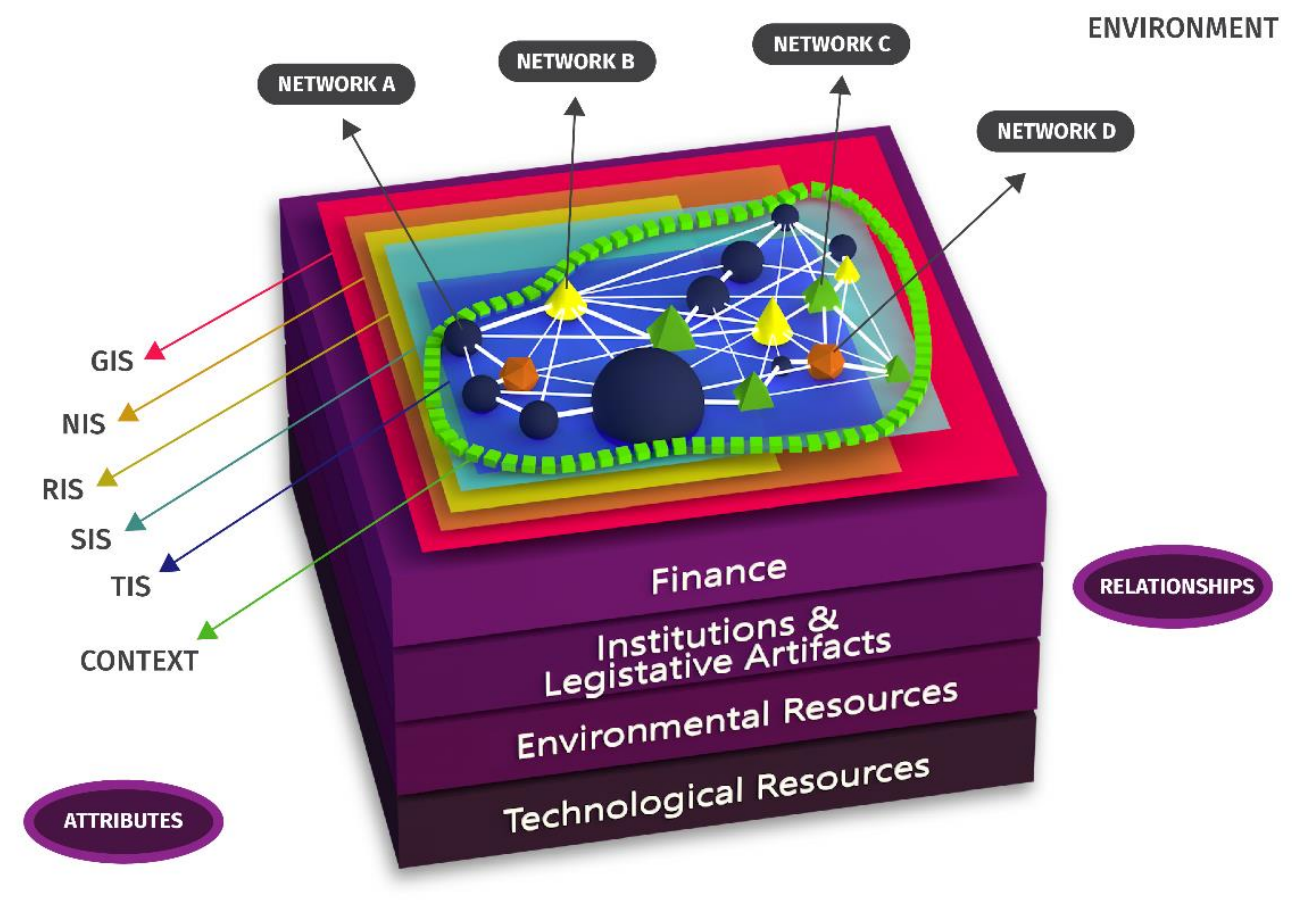

Figure 3: Research Framework

The following Research Questions have been defined within the scope of this study:

RQ1: How can Blockchain and SI be categorised based on the literature review?

RQ2: How can Blockchain and SI be fused into one SI framework?

RQ3: Which kind of new SI actors are expected to be included in the new SI framework?

RQ4: How are relationships in this new SI expected to be influenced by Blockchain?

RQ5: Which kind of attributes are expected to emerge in relation to SI?

\section{Method}

Systematic mapping was selected as the systematic review method to fuse Blockchain and SI information for the purpose of the Blockchain-based SI framework conceptual model (see Figure 4), while also permitting the researcher to identify any research gaps. The process for the systematic mapping study falls into five stages as depicted in Figure 4.

1. Definition of the Research Questions:(see Section 2.4)

2. Conducting the Search: This step is to search and find all of the scientific papers that are related to the research domains, i.e. Blockchain and SI. In the scope of this study, the following key search terms were selected: "Blockchain", "Smart Contracts", "Reputation", "Prediction Market", "Cryptocurrency", "Ethereum", "Backfeed”, "Distributed Ledger"; "Systems of Innovation”, "Innovation System” and "Triple Helix". This is in order to narrow down the focus of the study to cover both Blockchain and SIrelated studies accordingly. Due to the limited number of Blockchain-related innovation management studies, any Blockchain studies from the Business and Innovation domains were included in the first stage and to make sure that the topic was specific, they were reviewed in detail. Besides the relevance of the topics and the quality of the study, the studies were selected based on their method to make sure that they had either primary or secondary data-based results. The SI literature was used for the framework, actors and relationships perspectives. Along with a definition of the key search terms, titles, abstracts, and general exclusion criteria (see Figure 4), the scientific databases Scopus and Web of Science were selected with the main focus on high-quality papers, i.e. peer-reviewed papers published in the Business \& Management-related domains(Keupp et al., 2012,Greenhalgh et al., 2005). These papers were extended with two major contributors from the Blockchain-related domain, namely Tapscott and Tapscott (2016) with a citation rate of ' $600+$ ' and Swan (2015) with a citation rate of ' $1100+$ '. They were analysed in detail to enrich the chosen studies and to help shape the final framework, in addition to integrating Blockchain characteristics into the Blockchain-enabled SI framework.

3. Screening for Relevant Papers: As all papers found in the search queries were not necessarily related to the research questions, they needed to be assessed for their actual relevance. After using the search protocol in the scientific databases as described in Step 2, this step was about the screening of the papers 
that were relevant to the research questions outlined in Section 2.4. The same approach was introduced by Yli-Huumo et. al. (2016) and this was followed to look for relevant papers. In the first screening phase, the papers were screened based on their titles. If necessary, papers were excluded that were not relevant to the research topic. However, in case of difficulty determining the relevance of a paper on the basis of the title of the paper, the papers were passed through to the next stage for further reading where the abstracts of every paper were analysed. Papers with the following parameters were excluded: (1) papers without full-text availability, (2) non-English papers, (3) papers that had some other meaning than Blockchain used in computer science, (4) papers that were duplicates, and (5) articles, newsletters and grey literature. If a paper could fulfill all of these exclusion criteria and its abstract was considered to focus on Blockchain and SI, then it was eligible to be included in the next screening stage.

4. Key-wording Using Abstracts: This step was to classify all of the relevant papers using the key-wording process defined by Petersen et al. (2008). Key-wording was done in two steps. In the first step, we read the abstract and identified any keywords and concepts that reflected the contribution of the paper. The second step was to develop a higher level of understanding based on the keywords. The keywords were then used to classify the papers into various categories. After classifying all of the papers, the papers were read and changes were made to the classification when and where necessary. This resulted in a systematic map of clustered categories formed from all of the relevant papers on the research topic.

5. Data Fusion and Mapping Process ("Systems Thinking"): In this stage, a System Thinking approach was deployed to cover the three types of blocks in a system, namely components, relationships, and attributes. There may be two or more systems existing in parallel to each other that are connected by a number of components, which have direct relationships. In the scope of this study, it can be asserted that two systems, i.e. Blockchain and SI, may merge, once the purposes of the different systems align during the evolution (Klein and Sauer, 2016), which is related to the SI framework.

6. Systematic Map of Clustered Categories: (see Figure 6; Figure 7)

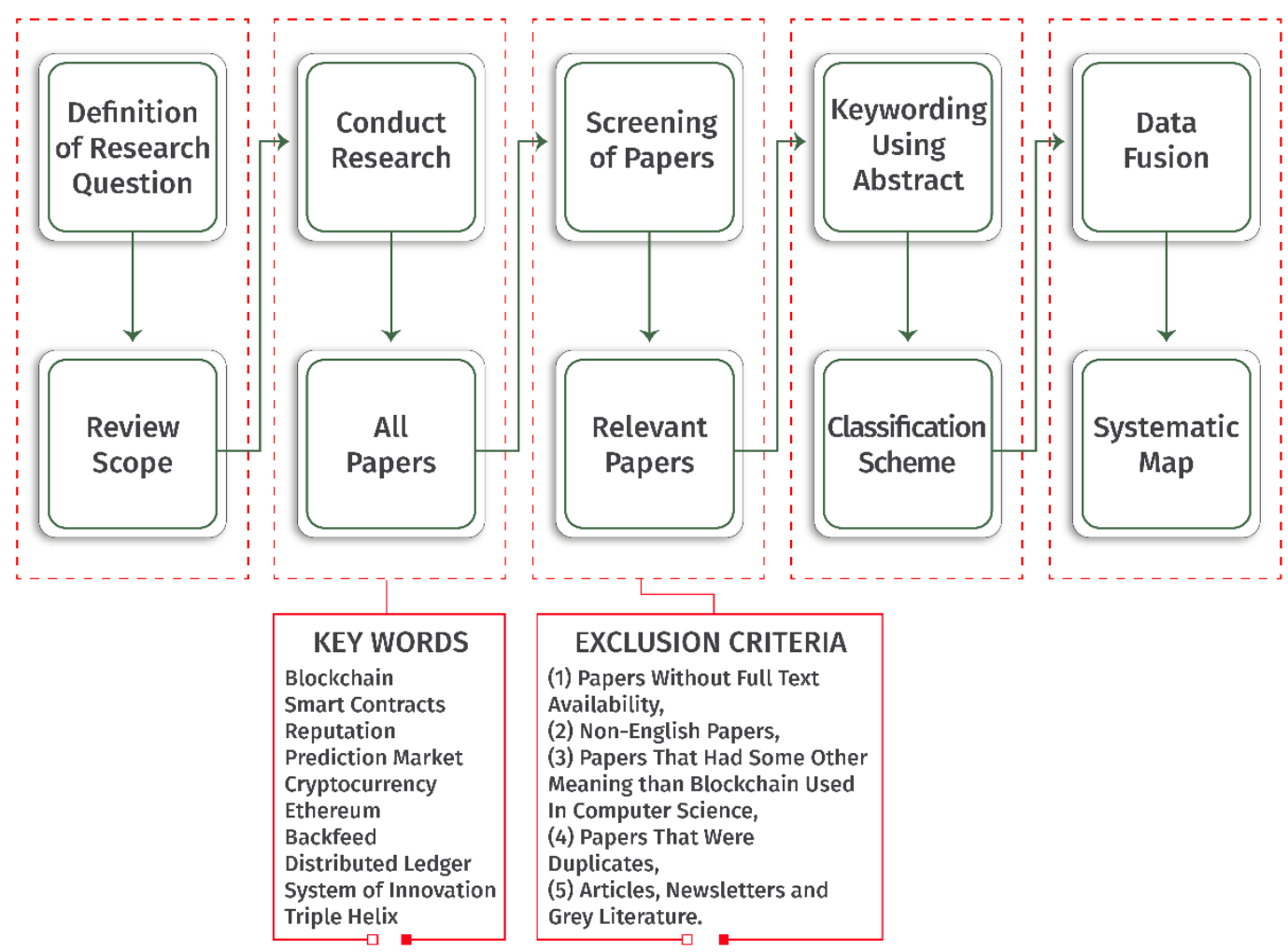

Figure 4: Systematic Mapping Method

\section{Results and Discussions}

This section discusses the results of the systematic mapping study as explained in Section 3. Firstly, the results of the searching and screening for relevant papers are outlined, followed by a discussion of the results. 


\subsection{Searching and Screening Results}

As of $21^{\text {st }}$ February 2019, the search protocol, as specified in Section 3, was deployed for all Blockchain- and SIrelated papers in the selected scientific databases, i.e. Scopus and Web of Science. Figure 5 depicts the corresponding workflow of the systematic mapping process. In total,900 Blockchain-related papers in Scopus and 693 Blockchain-related papers in Web of Science were identified and52 Blockchain-related papers were filtered down based on their titles. They were merged with SI-related papers in the later stages of the systematic mapping study process. When it comes to the SI related literature, all of the relevant SI papers were included in the systematic mapping process, for which 41 SI-related papers out of 759 SI-related papers emerged from Scopus and 49 SI-related papers out of 753 SI-related papers emerged from Web of Science. In total, 71 SI-related papers were filtered down and merged in the further stages of the systematic mapping study process, with additional criteria, i.e. quality and appropriateness for the Blockchain domain besides solely filtering according to their title to enable a much stricter selection of the SI-related papers.

Finally, 42 Blockchain-related papers and 38 SI-related papers were chosen after reading each paper entirely in line with a Systems Thinking approach. Besides two major books, namely Tapscott and Tapscott (2016) as well as Swan (2015), the relevant information required for data fusion was retrieved from the 37 Blockchain-related papers and 32 SI-related papers. These were chosen as the primary papers, during which the literature consisting of the intersection of Innovation \&Business Management and Blockchain domains were also considered in the data fusion stage. However, they were not included in the earlier stages of the systematic mapping process to enable the most comprehensive coverage of the systematic mapping study. The corresponding results are illustrated and discussed in Figure 6 and Figure 7.

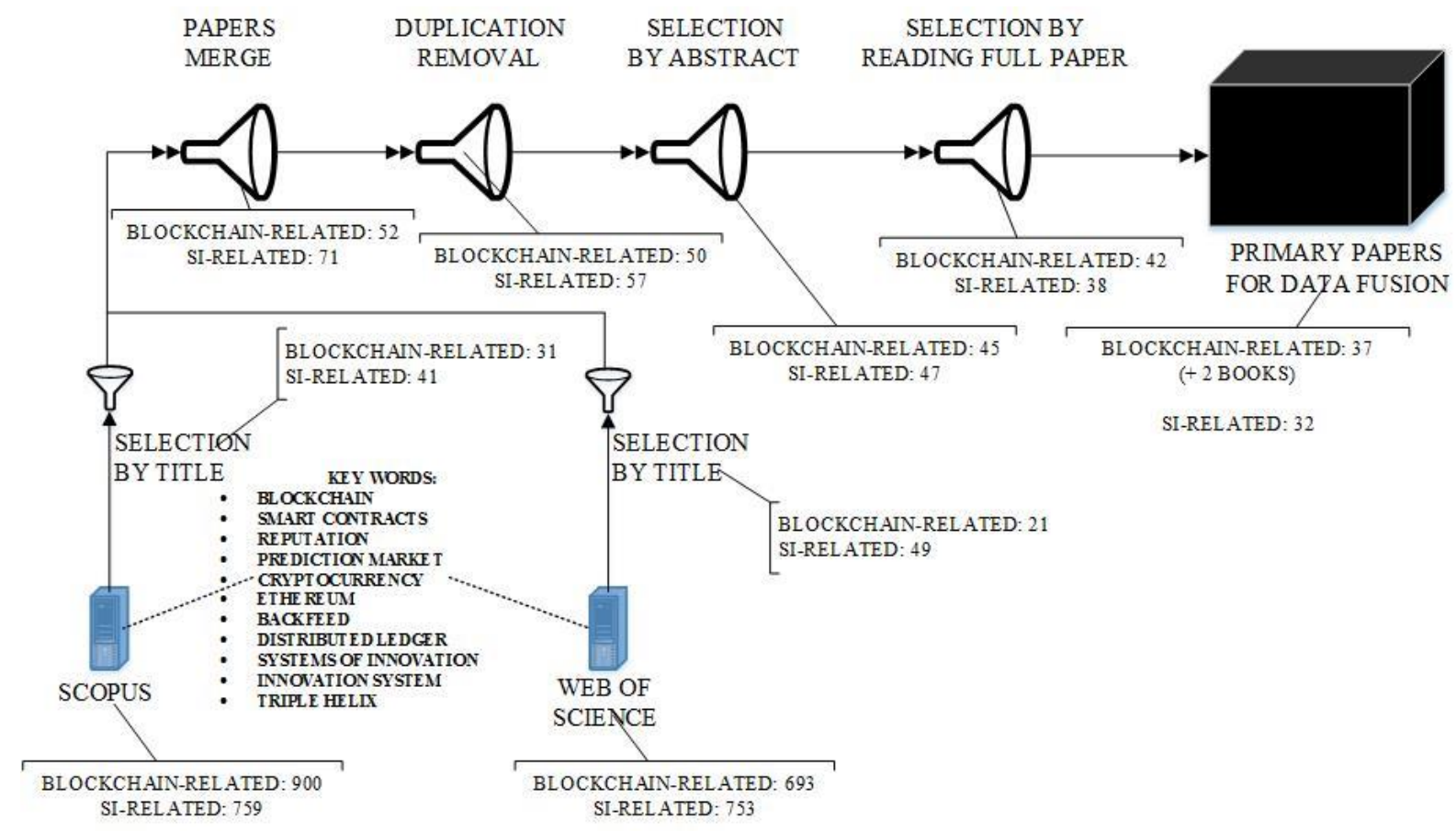

Figure 5: Workflow of the Systematic Mapping Study

\subsection{Classification Results}

The systematic mapping method, as outlined in Section 3, provides a structure of the type of studies and results that have been published so far and it goes on to categorise them. It gives a visual summary of its results so than an integrative systematic map of the SI and Blockchain (Figure 6) and Blockchain-enabled SI framework (Figure 6) is generated. Two different systems, such as Blockchain and SI, may be integrated with each other so long as their goals may be united, i.e. the Blockchain-enabled SI framework (Klein and Sauer, 2016).

The integrative systematic map shown in Figure 6outlines the findings of this study in a mind map format by superposing the Blockchain-related (bold font) and SI-related (bold, underlined and cursive font) findings according to the Systems Thinking approach. In fact, Systems Thinking provides a better interpretative approach to investigate such complex systems (Caputo et al., 2018), which is divided into three main categories as depicted in Figure 6. These include (1) "Components"; (2) "Relationships"; and (3) "Attributes" (Carlsson et al., 2002)."Components" consists of two further categories, specifically (1) actors (or organisations), such as individuals, companies, research institutions and (2) artefacts, such as technological resources (e.g. machinery 
equipment) or institutional (and legislative) artefacts (e.g. laws, standards)."Relationships" deals with the component connections, emphasising the dynamic SI characteristics, such as the feedback loops enabled by the presence of Blockchain tokens. "Attributes" describe the characteristics of a system that is influenced by the characteristics of Blockchain.

The Blockchain-enabled SI framework was generated in order to enable the widest inclusion of SI actors and to cover most of the actual SI landscape. On the one hand, it covers the Quintuple Helix (Carayannis and Campbell, 2010) consisting of five types of SI actors, namely (1) industry, (2) university, labelled as academia in Figure 6, (3) government, labelled as state in Figure 6, (4) citizen and (5) environment. The environment is considered to be another type of artefact. On the other hand, the work of Leitner et al. (2016) was applied which points to the emergence of new types of SI actors, such as collaborative innovators, creative consumers, and user innovators. In addition to both works in the SI literature which emphasise "a more fundamental blurring of the clear boundaries between actors' roles and functions" and the need for an enhanced approach to the SI landscape, Swan (2015) refers to the emergence of Blockchain-enabled SI actors in various parts of the SI landscape, e.g. finance or higher education. Thus, the six types of SI actors, related to the state, citizen, academia, intermediaries, financial actors, and industry domains, were integrated into the Blockchain-enabled SI framework, which increasingly shows distributed network characteristics (Ozcan and Islam, 2014; Pazaitis et al., 2017). The label of the SI actors was extended with the "Network" phrase.

"Artefacts" consists of four groups, namely (1) "Technological Resources" (Klein and Sauer, 2016), (2) "Environmental Resources", which is initially identified in the Quintuple Helix literature (Carayannis and Campbell, 2010) but was considered as an artefact later on, due to its passive character and findings in Blockchainrelated literature, such as Marsal-Llacuna (2017) and Sutherland et al.(2017), (3) "Institutions and Legislative Artefacts" (Klein and Sauer, 2016; Davidson et al., 2018) and (4) "Finance"(Swan, 2017).

"Relationships" consists of the "Proximity", "Collaboration" and "System Boundaries" and "Attributes" categories which in turn consist of (1) "Technology", (2) "Dimensions", (3) "Performance \& Efficiency" and (4) "Design Principles". As "Attributes" describes the system characteristics (Klein and Sauer, 2016), they also define how Blockchain-enabled SI is designed and operates. It also includes how the SI actors might interact, so "Attributes" may be assumed to be the most fundamental category.

In the next sections of this document, the integrative systematic map (Figure 7), will be discussed at the macro level as well as at the micro-level. Briefly, some of the critical findings are that(a) distributed and collaborative innovation is emerging, (b) it is supported by reputation systems, so, therefore (c) system boundaries will become blurred, (d) Blockchain may democratise entrepreneurship and(e) the Blockchain-enabled SI platform is driven by technological drivers. 


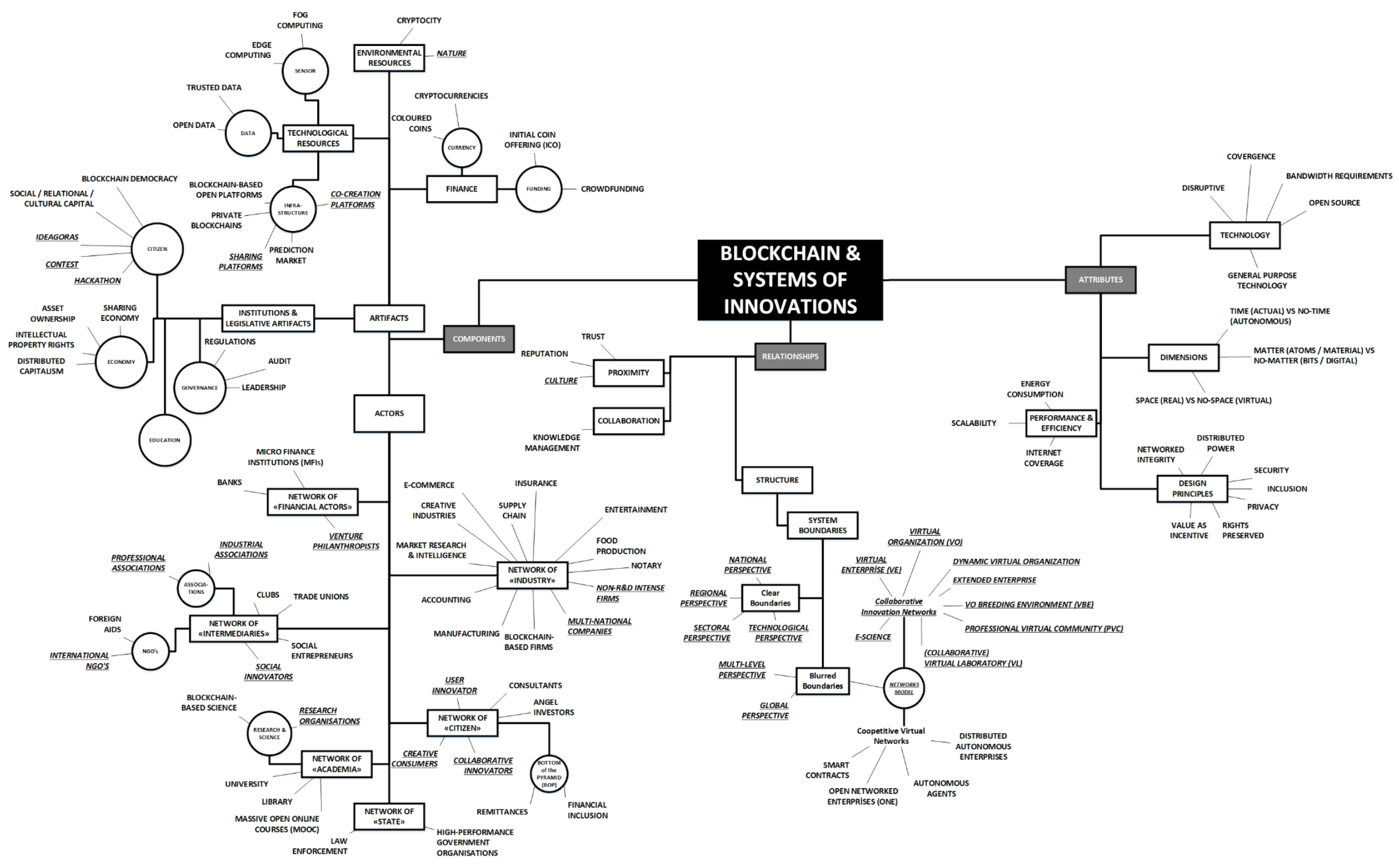

Figure 6: Integrative Systematic Mapping of SI and Blockchain 


\subsection{Framework}

Reflecting on the Systems Thinking approach, Figure 7 depicts the Blockchain-Enabled SI Framework. This is a visualisation of the systematic map and it has to be considered the extended version of the research framework in Figure 3.

The new SI consists of four types of new SI actors, specifically (1) disruptive organisations, i.e. Blockchainenabled firms, Micro-Finance Institutions, High-Performance Government Organisations etc, (2) a new class of innovators, i.e. Creative Consumers, Collaborative Innovators, (3) a new class of strategic individuals, i.e. Venture Philanthropists and (4) BoP as an emerging class, to be particularly considered in relation to Financial Inclusion. On the other hand, the SI actors are expected to rely on a different type of Blockchain-enabled artefact, shown as layers in Figure 7, specifically: (1) finance, (2) institutional and legislative artefacts, (3) environmental and (4) technological resources. SI actors and SI artefacts will be discussed in Section 4.4.

Blockchain-enabled SI relationships, shown on the right side of Figure 7, are expected to lead to collaborative, distributed networks based on (1) proximity leading to (2) blurred SI boundaries. Particularly influenced by the Blockchain-related literature, the findings related to Blockchain-enabled SI attributes can be categorised as follows: (1) design principles, (2) performance \& efficiency, (3) dimensions and finally, (4) technology. The SI relationships and attributes will be discussed in Section 4.5 .

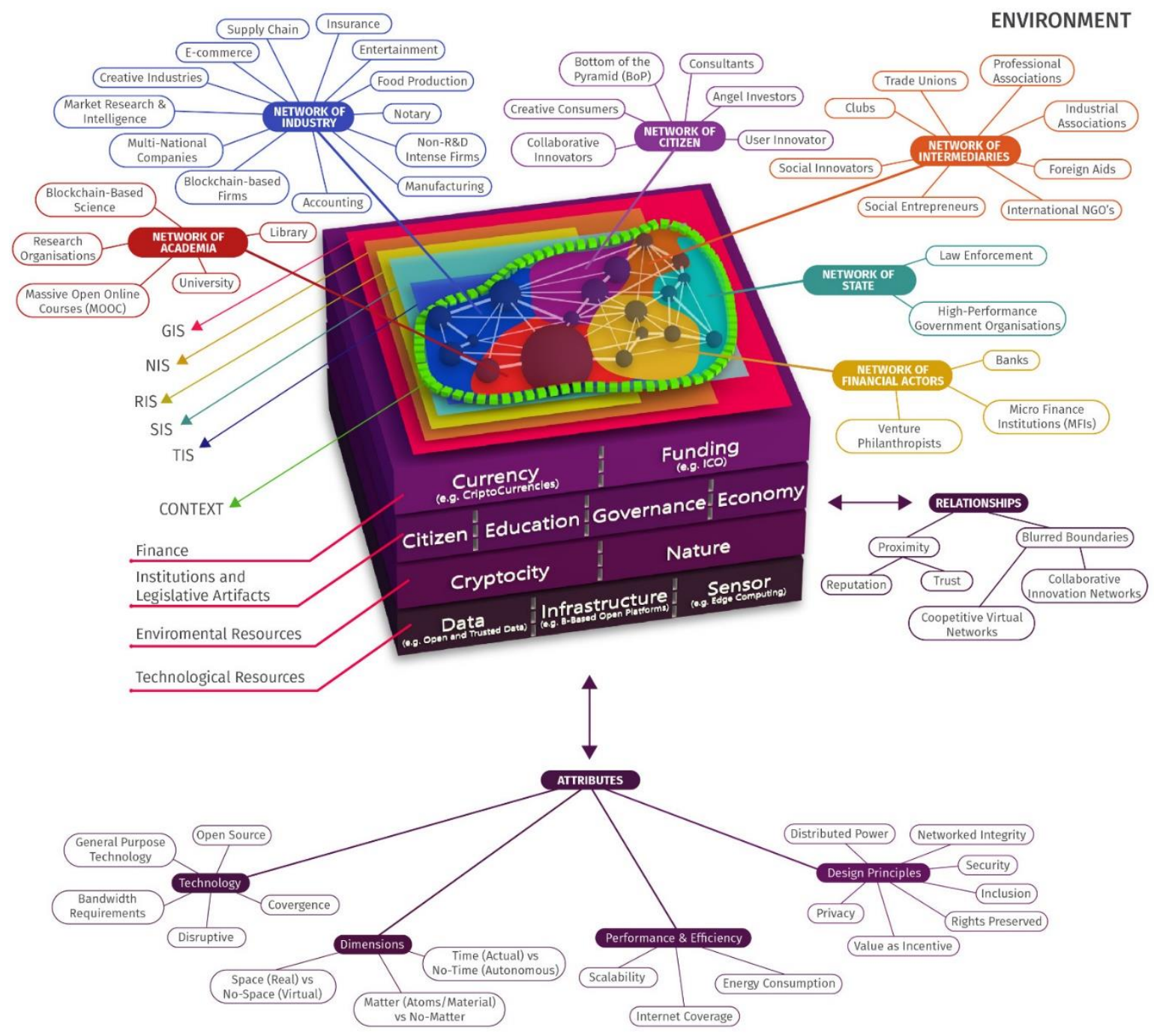

Figure 7: Blockchain-Enabled SI Framework 


\subsection{Blockchain-enabled SI Actors and Artefacts}

The Blockchain-enabled SI framework consists of SI actors showing distributed network characteristics. In other words, it is difficult to assign clear roles to the SI actors, so they can shift between the various actor categories. Blockchain-enabled SI actors consist of the state, citizen, academia, intermediaries, financial actors and industry domains (see Figure 6). Furthermore, the size of the nodes in Figure 7reflect the idea that SI actors may have different importance and strength in this new SI framework.

"Network of Citizen" consists of SI actors, such as creative consumers, angel investors, and BoP (Aste et al., 2017; Leitner et al.), while Blockchain is expected to empower citizens for innovation. The information needed to innovate becomes widely available to citizens, so that they may even create innovations by themselves (Leitner et al., 2016; von Hippel, 1976). Furthermore, while constituting billions of people in the developing world, BoP is expected to benefit from Blockchain technology significantly. As "Internet of Governance", Blockchain may address the main difficulties of BoP, such as land registration, digital identity, financial inclusion and financing for entrepreneurs. This includes Blockchain-based solutions, such as digital identities or remittance (MarsalLlacuna, 2017). Entrepreneurship is also expected to be influenced by Blockchain (Chen, 2017). In this context, Blockchain may democratise access to opportunities across the globe so then angel investors, besides professional and accredited investors, may invest in projects and trade Blockchain tokens (Chen, 2017; Fisch, 2019). Furthermore, in line with financial inclusion, Blockchain could unleash the untapped pool of entrepreneurs at BoP worldwide (Larios-Hernández, 2017).

Blockchain has the potential to transform the state into the "Network of State", enabling efficient and transparent government operations (Manski, 2017; Olnes et al., 2017) while reducing financial barriers for BoP (Swan, 2017). Many governments are already experimenting with various Blockchain-enabled services, including digital identity, the storing of judicial decisions, e-voting, business licenses, passports, criminal records and even tax records (Olnes et al., 2017). Furthermore, the data of citizens could be migrated to a single Blockchain-enabled platform, currently existent in multiple databases (Wolfond, 2017).

Blockchain may transform academic institutions to global academic nodes consisting of faculty, students, and institutions, i.e. "Network of Academia" (Janowicz et al., 2018; Sharples and Domingue, 2016; Tapscott and Tapscott, 2017b). "Network of Academia" could benefit from Blockchain technology as follows: (1) editing, reviewing and publishing academic work, (2) managing scientific data and (3) intellectual property, (4) democratising the decision processes in science and (5) enabling an award mechanism for the research community (Tapscott and Tapscott, 2017b; Sharples and Domingue, 2016). Blockchain could tackle the various weaknesses of Massive Open Online Courses (MOOC), including the lack of ability to ascertain the origin, validity, and accountability of the knowledge that is created, shared, and acquired (Funk et al., 2018).

Scholars, such as Li et al.(2018), Norta (2015), Nowiński and Kozma(2017) and O'Leary (2017), exemplify how Blockchain could disrupt different existing industries, including aviation, insurance, entertainment, energy, and real estate(Ying et al., 2018; Gatteschi et al., 2018; Andoni et al., 2019; Veuger, 2018) and transform traditional business functions, such as accounting, auditing, sales and marketing, manufacturing, R\&D, logistics and supply chain, leading to "Network of Industry". Scholars claim that businesses implementing Blockchain may gain competitive advantages where their core operations are streamlined, their transaction costs are decreased and their intellectual property ownership and payments are made more transparent and automated (Nowiński and Kozma, 2017; O'Leary, 2017). For instance, Blockchain appears to be beneficial for the energy market while offering disintermediation, transparency, tamper-proof transactions and novel solutions for empowering consumers as well as small renewable energy producers (Andoni et al.,2019). Furthermore, an increasing number of applications for the sharing-economy in the energy sector are also expected, which has prompted several scholars to refer to novel market models and energy democratisation.

"Network of Intermediaries" covers the emergent type of SI actors whose activities can be considered as a byproduct of their primary function or whose activities do not primarily target innovation but who have an indirect impact on innovation (Leitner et al., 2016), such as social entrepreneurs and innovators or NGOs. Social entrepreneurs and innovators aim to serve the public interest without profit maximisation while distinguishing themselves from traditional voluntary organisations (Dionisio, 2019). There are various arguments for integrating social innovation as a relevant element of SI, be it on a national, regional or local level (Dionisio, 2019; Leitner et al., 2016). When it comes to NGOs, Till et al. (2017) exemplifies how Blockchain could enable universal health coverage by removing third-party financial intermediaries in transparent, secure and accountable means. This is particularly important for NGOs aiming to provide foreign aids as efficiently as possible.

Oh and Shong (2017), Fisch (2019) and Tapscott and Tapscott (2017c) point to the SI actors such as banks, Micro Finance Institutions (MFI's) and venture philanthropists, i.e. "Network of Financial Actors". Financial institutions currently rely only on credit scores. They exclude critical inputs such as reputation, which are not easy to formulate, document and use. With features such as efficient attestation, instant, and frictionless value transfer, 
better risk management and open-source characteristics, Blockchain might disrupt financial institutions within the current social and economic systems (Tapscott and Tapscott, 2017c). Blockchain could easily attract donors to source funds and opportunities worldwide (Swan, 2017) where particularly venture philanthropists can emerge as a critical SI actor.

The new framework is based on different layers, namely (1) technological resources (data, infrastructure, and sensor), (2) environmental resources, (3) institutional and legislative artefacts and (4) finance (Figure 7). The Technological resources layer consists of data, infrastructure, and sensors.

The Environmental Resources layer consists of crypto-city and nature. The crypto-city is strongly related to the technological resources layer, where citizens may access raw data such as traffic patterns or energy usage. This is retrieved from sensors surrounding the city, enabling the higher engagement of citizens in decision-making and the implementation of policies, e.g. controlling government budget and expenditures, while better policy choices are enabled (Marsal-Llacuna, 2017; Manski, 2017). As many of the environmental challenges, i.e. nature, related to natural resources and maintaining ecosystem services are caused by a lack of trust and confidence in the rules governing exchange and possession, Blockchain could (1) enable more transparency about individual and collective action, (2) reduce bureaucracy and power asymmetries, (3) incentivise environmentally sustainable actions, (4) reinforce the entitlement to use a natural resource and (5) substantiate claims of reduced environmental impact (Sutherland et al., 2017).

The Institutions and Legislative Artefacts layer consist of citizen, education, governance, and economy. This is about regulating the decision-making processes among the SI actors involved in a collective problem, leading to the creation, reinforcement, or reproduction of social norms and institutions (Shermin, 2017). This is also where Blockchain could disrupt the traditional governance structures which emphasise centralisation and hierarchy with various degrees of rigid top-down command and control decisions making rule-sets. Thus, bureaucracy is reduced, principal-agent issues and the subsequent moral hazards are addressed (Davidson et al., 2018; Shermin, 2017).

"Initial Coin Offering" (ICO) is a good example of the Finance layer, consisting of currency and funding.ICO is a new generation of innovations in entrepreneurial finance, through which capital may be raised by selling Blockchain tokens, e.g. cryptocurrencies to a group of investors. (Fisch, 2019).ICO's enable entrepreneurs, who usually have trouble meeting investors, to raise large amounts of funding with minimal effort as the fundraising process is highly inefficient and localised (Chen, 2017; Fisch, 2019). Furthermore, ICO's could enable financial inclusion while significantly leveraging the level of BoP (Larios-Hernández, 2017).

In summary, this study asserts that Blockchain, as a disruptive institutional technology, will influence the definition and function of some of the SI actors. It will also introduce new SI actors by enabling better coordination, ultimately causing the emergence of collaborative networks from which BoP will benefit particularly.

\subsection{Blockchain-enabled SI Relationships and Attributes}

As "Internet of Governance", Blockchain is expected to influence SI relationships by transforming the SI landscape to a non-hierarchal, distributed and decentralised collaborative network (Ozcan and Islam, 2014; Pazaitiset al., 2017). Loosely affiliated network actors could collaboratively contribute to the community's goal on a projectspecific or ad hoc basis, whereby a network actor, i.e. SI actor, can be an individual or one facet of an individual, or a group of individuals, or any independent entity. Blockchain could not only deal with the management of the resources but it could also enable the social practice of working together for a common purpose, i.e. communing (Pazaitis et al., 2017). As demonstrated with Bitcoin, i.e. a pioneer of Blockchain commons, Blockchain may easily scaleup commons, which are usually missing an intrinsic incentive mechanism inherent in their governance structure, so that new contributors are attracted (Pazaitis et al., 2017, Tapscott and Tapscott, 2016).

The Backfeed platform may be considered as a perfect example of how value can be assessed and distributed in Blockchain commons (Davidson et al.,2018; Pazaitis et al., 2017). With an additional trust layer and new consensus mechanism, i.e. Proof of Value, Backfeed is an enhanced Blockchain platform. This is where a new type of governance for decentralised collaboration and a reward system is enabled. Backfeed traces the reputation of each actor based on their contribution to the community, derived from other actors (Davidson et al., 2018). Thanks to the design principles of Blockchain, Backfeed shows how distributed SI actors can be coordinated. Furthermore, Backfeed also exemplifies how Blockchain tokens may quantify proximity factors, such as reputation. This is so then the trust may be transparently established in an open market in comparison to vertically integrated and isolated traditional companies, which is fundamental for successful innovation (Audretsch and Feldman, 1996; Nooteboom, 1999). Thus, Blockchain is expected to spread innovation activities to the entire SI landscape so then innovation is no longer the sole privilege of centralised organisations, which are in a position to 
control and manipulate innovation in line with their benefits and thus to hinder efficient SI (Tapscott and Tapscott, 2016).

Blockchain-enabled SI attributes consist of (1) design principles (2) performance and efficiency, (3) technology and (4) dimensions. Tapscott and Tapscott (2016) introduced the seven design principles of Blockchain with an impact on SI as well: ((1) networked integrity and ensured trust in transactions thanks to consensus mechanisms (2) distributed power across the network with no single point of control,(3) Blockchain tokens as an incentive and award mechanism, (4) security delegated to the entire network, (5) adaptable privacy for all SI actors, (6) transparent and enforceable ownership rights and(7) inclusion, particularly financial inclusion.

Performance and efficiency issues in relation to Blockchain are highly related to (1) scalability, (2) Internet coverage and (3) energy consumption. As Chauhan et al. (2018) claim, with the increasing popularity and adoption of Blockchain, it is highly critical to think about a very basic problem in the initial design, i.e. the lack of scalability. This is particularly related to the mining nodes responsible for verifying each transaction. This has become the bottleneck in the transaction process of the Blockchain platform due to an increased number of network members. There is an extremely long waiting time for a new block to be mined. The lack of scalability is also related to the energy-intensive design of Blockchain, causing the inefficient use of electricity equivalent to powering an entire country, such as Denmark (Andoni et al., 2019). Connectivity innovations, such as the Internet, could help BoP in many respects. It is transformative in nature and the backbone of many inclusive technologies such as Blockchain. Connectivity is the glue that binds the BoP and the rest of the world together. Mendonça et al. (2015) pointed out the importance of connectivity on BoP, particularly from the digital inclusion perspective, while many governments increasingly address the digital divide in line with the Sustainable Development Goals (Kewell et al., 2017).

SI attributes from the technology perspective are related to (1) the open-source structure, (2) disruptive generalpurpose technology, (3) the convergence of different technologies and (4) the low requirement for bandwidth. Blockchain is an open-source, distributed, and trustless software on the Internet (Davidson et al.2018) enabling secure and reliable mass collaborations and in turn, further enabling a new kind of organisation and society (Pazaitis et al., 2017). Scholars such as (Davidson et al., 2018) refer to Blockchain as the new generation GPT, combining different technologies such as mathematical cryptography, open-source software, computer networks, and incentive mechanisms. It might show pervasive characteristics due to its low requirement for bandwidth (Tapscott and Tapscott, 2016).

By extending Carlsson et al's (2002) claim stating that the time dimension of SI represents a snapshot of the system at a particular point in time which may differ substantially from another snapshot of the same system at a different time, the Blockchain-enabled SI framework may expand into following dimensions: (1) space, (2) matter and (3) time. In this context, Blockchain introduces a new Blockchain-specific dimension, i.e. Blocktime (Swan, 2016), which is used to measure time. This is besides physical realities such as human time and it provides the possibility of creating another dimension of time. Blocktime is the in-built time of Blockchain, which may be measured as the chain of time needed for confirmation of a certain number of blocks. Blocktime, as a feature of smart contracts, may become more interesting in the scope of a Blockchain-enabled SI framework when various contractual states are created and made dependent on events or changes in condition.

From the perspective of the Blockchain-enabled SI attributes perspective, this study asserts that the system attributes will be particularly influenced by Blockchain's design principles, such as Proof of Work. They clearly define how such systems should function. Therefore, issues such as scalability and energy consumption will be very important, which has currently not been addressed in recent SI studies.

\section{Conclusions}

GPTs have long driven modern market capitalism through creative destruction and productivity in the form of growth. While still in the premature stage, Blockchain is also referred to as a new GPT (Davidson et al., 2018). Blockchain shows unique features as an institutional disruptive technology of governance, with the potential to reconfigure all aspects of our civilisation by replacing ledgers digitally (Davidson et al., 2018). This points particularly to a new level of criticality. Scholars of the Innovation Management domain must consider the longerterm implications of Blockchain for the SI landscape (Warnke et al., 2016). Thus, this study aims to cover this research gap by identifying and fusing together all of the required Blockchain and SI-related information for the Blockchain platform-based SI framework.

The stream of the literature shows that Blockchain may be defined in principle as a database that produces a trustless consensus for anything that may be digitalized, which is limited by the coverage of the Internet. Furthermore, it is shown that value serves as a perfect coordination mechanism in innovation activities while unique Blockchain features transform the innovation activities in the SI landscape into Blockchain commons. This 
is by redefining (1) how value is produced, (2) how value is recorded and (3) how value is actualised (Pazaitis et al., 2017). However, to avoid techno-determinism, Blockchain's influence on innovation needs to be investigated further, supported by the primary data in order to understand how wide the deployment of Blockchain in real-life applications can be realised while considering complexities of society. In this scope, this study comes up with the theoretical and practical implications listed in Table 1 and Table 2 while addressing the broad spectrum of stakeholders. This includes the scholars and policymakers who are expected to be confronted with the associated benefits as well as the potential contractions caused by the appearance of Blockchain.

Table 1 outlines the theoretical implications, namely (1) Systems of Innovations, (2) Network Theory, (3) Institutional Theory and (4) Commons Theory. In the scope of SI, it is outlined how Blockchain will transform the factors related to SI. "Network Theory" explains how the design principles of Blockchain, such as the consensus mechanisms, disrupt the centralised network actors. "Institutional Theory" illustrates how Blockchain, as a disruptive institutional technology, might transform innovation. Furthermore, "Common Theory" explains how Blockchain influences collaborative actions for the common good.

\begin{tabular}{|c|c|}
\hline $\begin{array}{l}\text { Relevant Models } \\
\text { and Theories }\end{array}$ & Theoretical Implication \\
\hline $\begin{array}{l}\text { of } \\
\text { ons }\end{array}$ & $\begin{array}{l}\text { 1. The literature shows that Blockchain will transform the definition of the SI actors } \\
\text { in traditional SI studies into network actors in a distributed form. This can be either } \\
\text { an individual or one facet of an individual, or a group of individuals, or any } \\
\text { independent entity, increasingly showing similar characteristics to an open-source } \\
\text { society during the Internet era. } \\
\text { 2. Blockchain is expected to enable a new type of democratic, self-governing and } \\
\text { collaborative innovation mode in an increasingly international and highly complex } \\
\text { spatial configuration. } \\
\text { 3. It is shown that Blockchain challenges assumptions about internalising } \\
\text { organisational functions. } \\
\text { 4. It seems that Blockchain is expected to abolish the traditional hierarchy between } \\
\text { people in organisations, thereby influencing organisational proximity. } \\
\text { 5. It is likely that the rationales for the policies introduced by governmental institutions } \\
\text { will be significantly reduced. } \\
\text { 6. It appears that the role of traditional SI actors will lose their importance in NIS. } \\
\text { They will be replaced by private collectives of open innovation and innovation } \\
\text { commons. } \\
\text { 7. Following the BoP and frugal innovation models and theories, the users and } \\
\text { innovators from the BoP appear to have a higher possibility of involving innovation } \\
\text { activities in a Blockchain-based SI structure. } \\
\text { 8. It appears to be that traditional SI studies, which consist of brick-and-mortar } \\
\text { institutions such as academia or the state, will increasingly recognise the emerging } \\
\text { role of informal institutions. } \\
\text { 9. Thanks to Blockchain tokens, the SI actors are expected to obtain a new way of } \\
\text { raising funds and also a new way of building ecosystems. }\end{array}$ \\
\hline Network Theory & $\begin{array}{l}\text { 1. The literature shows that centralised positions will no longer be a source of power } \\
\text { in network theory. } \\
\text { 2. It is likely that Blockchain eliminates the ability of any single actor to control the } \\
\text { network, i.e. balance of power theory. } \\
\text { 3. Blockchain is expected to disrupt closed networks consisting of a few centralised } \\
\text { strong network actors. This is so then the innovation activities are distributed across } \\
\text { the entire network. } \\
\text { 4. It is shown that Blockchain could quantify proximity factors such as reputation, and } \\
\text { influence the theory of the dominant actors. The SI actors may have a different role } \\
\text { and importance in the new SI framework. }\end{array}$ \\
\hline Institutional Theory & $\begin{array}{l}\text { 1. The institutional theory follows the fundamental assumption that formal } \\
\text { organisations are based on legitimacy claims to solve coordination issues. However, } \\
\text { Blockchain decreases the importance of organisational legitimacy claims. } \\
\text { 2. Blockchain is expected to enable "trustless" cooperation and lower transaction costs } \\
\text { between innovation actors without the need for a central authority by improving the } \\
\text { efficacy of economic coordination. }\end{array}$ \\
\hline Commons Theory & $\begin{array}{l}\text { 1. Collaborative networks strongly rely on common social norms and values, whereas } \\
\text { Blockchain is expected to significantly transform this. }\end{array}$ \\
\hline
\end{tabular}




\begin{tabular}{|l|l|}
\hline $\begin{array}{c}\text { Relevant Models } \\
\text { and Theories }\end{array}$ & \multicolumn{1}{c|}{ Theoretical Implication } \\
\hline & $\begin{array}{l}\text { It seems that Blockchain is expected to show characteristics similar to the Internet, } \\
\text { which is curated, orchestrated and governed by a collection of various collaborative } \\
\text { actors with less or no intervention from governments. } \\
\text { It is likely that the creation of value will take place collaboratively with many small- } \\
\text { scale contributions from the decentralised innovation actors. This is mainly } \\
\text { concerned with the accompanying social practice of working together for a common } \\
\text { purpose. }\end{array}$ \\
\hline
\end{tabular}

Table 1: Theoretical Implications

Table 2 outlines the following practical implications: (1) industry, (2) government, (3) academia, (4) collaborative innovation, (5) R\&D and Innovation Management, (6) artefacts, (7) trust and (8) digital funds \& finance. "Industry", "State" and "Academia" outline the practical implications for the SI actors. "Collaborative Innovation" consists of the practical implications from the Blockchain commons perspective while "R\&D" and "Innovation Management" outline the practical implications to maximising the benefits of the SI actors in their innovation activities. "Trust" points to the changing role of trust in innovation activities, while "Digital Funds \&Finance" outlines Blockchain's practical implications for finance.

\begin{tabular}{|c|c|}
\hline $\begin{array}{c}\text { Practical } \\
\text { Perspective }\end{array}$ & Practical Implication \\
\hline Industry & $\begin{array}{l}\text { 1. Firms should prioritise accounting, auditing, sales and marketing, manufacturing, } \\
\text { R\&D, logistics and supply chain functions in their strategy with regards to } \\
\text { Blockchain transformation. This is in addition to redefining their business models. } \\
\text { 2. Financial institutions should consider including Blockchain in their financing } \\
\text { processes, which currently excludes person-related critical inputs, such as } \\
\text { reputation. } \\
\text { 3. Players in the energy sector should focus on Blockchain-enabled distributed } \\
\text { infrastructure solutions in line with the sharing economy concept to maximise their } \\
\text { competitive advantage in an energy market-facing transformation. } \\
\text { 4. As demonstrated with the Backfeed or Steemit platform, the software industry, } \\
\text { aiming to realise or take part in Open Source projects, could work on the } \\
\text { development of such collaborative platforms. } \\
\text { 5etwork operators should continue to extend their low band networks as Blockchain } \\
\text { is expected to operate in low bandwidth. }\end{array}$ \\
\hline State & $\begin{array}{l}\text { 1. Governments, when considering to improve their citizen services, should introduce } \\
\text { and investigate the policies supporting Blockchain-based identity validation } \\
\text { frameworks. } \\
\text { 2. The applicability of Blockchain depends on the coverage of the Internet. Thus, } \\
\text { governmental institutions should introduce policies against digital exclusion. } \\
\text { 3. Governmental institutions should introduce policies to promote sustainable } \\
\text { Blockchain applications. The software industry should work on the modification of } \\
\text { Blockchain design principles. } \\
\text { 4. Policymakers should introduce innovation policies to strengthen the role of MOOCs } \\
\text { to contribute to the achievement of SDGs. }\end{array}$ \\
\hline Academia & $\begin{array}{l}\text { 1. Brick-and-mortar educational institutions should consider how to transform their } \\
\text { operations into Blockchain-based MOOCs. } \\
\text { 2. To achieve SDGs, academic and governmental institutions should investigate and } \\
\text { introduce policies and foster efficient Blockchain-enabled sharing economy use in } \\
\text { cooperation with other SI actors, such as academia and NGO's. } \\
\text { 3. Academic institutions need to investigate the collaborative innovation processes and } \\
\text { activities based on smart contracts and DAOs. This is so than proper policies may } \\
\text { be introduced to enable collaborative innovation. } \\
\text { 4. Governmental institutions and academia should work on advanced Blockchain- } \\
\text { enabled data governance mechanisms supported by proper policies in order to } \\
\text { transform cities into crypto-cities to foster innovative outcomes. }\end{array}$ \\
\hline $\begin{array}{l}\text { Collaborative } \\
\text { Innovation }\end{array}$ & $\begin{array}{l}\text { 1. The industry may investigate introducing Blockchain-enabled participatory and } \\
\text { citizen-centric solutions. } \\
\text { 2. The academic world should investigate existing collaborative innovation networks } \\
\text { such as Wikipedia. They propose supportive Blockchain policies to increase their } \\
\text { efficiency. }\end{array}$ \\
\hline
\end{tabular}




\begin{tabular}{|c|c|}
\hline $\begin{array}{c}\text { Practical } \\
\text { Perspective }\end{array}$ & Practical Implication \\
\hline $\begin{array}{l}\text { R\&D and } \\
\text { Innovation } \\
\text { Management }\end{array}$ & $\begin{array}{l}\text { 1. Entrepreneurs and smaller companies should investigate the methods of efficient } \\
\text { collaboration in Open Innovation initiatives with Blockchain technology. } \\
\text { 2. Larger companies may consider refining their business models to tackle the } \\
\text { increasing competition triggered by Blockchain-enabled Open Innovation } \\
\text { initiatives. } \\
\text { 3. Governmental institutions need to define innovation policies to maximise the Open } \\
\text { Innovation initiatives and to align with national innovation strategies in order to } \\
\text { increase their national competitiveness. }\end{array}$ \\
\hline Artifacts & $\begin{array}{l}\text { 1. The academic institutions and private organisations dealing with Blockchain } \\
\text { development should improve the design principles of Blockchain. This is in order } \\
\text { to avoid technological drivers such as data and energy, which tend to become a } \\
\text { bottleneck of Blockchain-enabled systems. } \\
\text { 2. Policymakers should investigate how the automatisation of administrative and } \\
\text { executive functions embedded within the DAOs may disrupt the SI landscape in } \\
\text { order to introduce efficient policies to regulate the DAOs accordingly. }\end{array}$ \\
\hline Trust & $\begin{array}{l}\text { 1. Policymakers can introduce policies to tackle the information asymmetry related to } \\
\text { Blockchain. } \\
\text { 2. Governmental and academic institutions should investigate how to enable trust in } \\
\text { the non-digital dimension of Blockchain, such as the concentration of mining nodes. }\end{array}$ \\
\hline $\begin{array}{l}\text { Digital Funds } \\
\text { \&Finance }\end{array}$ & $\begin{array}{l}\text { 1. Entrepreneurs and small firms, who experience inefficient and localised fundraising } \\
\text { processes, should investigate whether and how to realise successful ICO's. } \\
\text { 2. Blockchain is expected to attract strategic individuals and venture philanthropists } \\
\text { so that governments should introduce proper policies at a global scale for maximum } \\
\text { impact. }\end{array}$ \\
\hline
\end{tabular}

Table 2: Practical Implications

The key lessons learnt in this study can be broken down based on the SI and Blockchain-related practical findings.

\begin{tabular}{|c|c|}
\hline Study Perspectives & Key Lessons Learnt \\
\hline SI Perspective & $\begin{array}{l}\text { 1. The Citizen will be no longer be a passive receiver of innovation. They will become } \\
\text { knowledgeable individual innovators as the information needed to innovate } \\
\text { becomes widely democratised and available to many consumers (von Hippel, 1976). } \\
\text { 2. The Citizen will show that they have a higher level of engagement in the decision- } \\
\text { making processes as experimented with in prediction markets, resulting in better } \\
\text { policy choices that are collectively supported. } \\
\text { 3. Governmental institutions will be transformed so then the bureaucracy is reduced } \\
\text { and higher operational efficiency is enabled. }\end{array}$ \\
\hline $\begin{array}{l}\text { Blockchain } \\
\text { Perspective }\end{array}$ & $\begin{array}{l}\text { 1. Performance and efficiency problems, including scalability, Internet coverage, and } \\
\text { energy consumption, might hinder Blockchain from becoming a GPT. } \\
\text { 2. Blockchain can particularly fuel Open Innovation (OI) realisations as it allows for } \\
\text { the capture of values created by the community members. } \\
\text { 3. DAO's may eliminate the need for human management involvement as well as } \\
\text { traditional central coordination, thus disrupting traditional governance structures. } \\
\text { 4. The pervasive deployment of smart contracts and DAO's would also eliminate the } \\
\text { need for in-house expert know-how. This can be outsourced to subcontractors. }\end{array}$ \\
\hline
\end{tabular}

Table 3: Key Lessons Learnt

This study has some limitations imposed by techno-determinism, as it reflects on the key findings of Blockchainrelated literature, pointing to the emergence of new forms of Blockchain-based governance for innovation. Unfortunately, they ignore the complexity of human interactions and social organisation. In this respect, Blockchain is very similar to the development of the Internet, which transformed itself into a more oligopolistic structure many years later, dominated by few but strong network actors, such as Google. Overall, future studies should address the following limitations: (1) system perspective, (2) design principles, (3) governance, (4) regulation, (5) collaboration and (6) the human, social, cultural and organisational aspects.

\section{References}

1. Aste, T., Tasca, P., and Di Matteo, T., (2017), "Blockchain technologies: The foreseeable impact on society and industry". Computer, Vol.50 No.9, pp.18-28. 
2. Andoni, M., Robu, V., Flynn, D., Abram, S., Geach, D., Jenkins, D., ... \& Peacock, A, (2019), "Blockchain technology in the energy sector: A systematic review of challenges and opportunities", Renewable and Sustainable Energy Reviews, 100, 143-174

3. Audretsch, D. B., and Feldman, M. P., (1996), "R\&D spillovers and the geography of innovation and production", The American Economic Review, Vol.86 No.3, pp.630-640.

4. Binz, C., and Truffer, B., (2017), "Global Innovation Systems-A conceptual framework for innovation dynamics in transnational contexts”, Research Policy, Vol.46 No.7, pp.1284-1298.

5. Bresnahan, T. F., and Trajtenberg, M. (1995). "General purpose technologies 'Engines of growth'?", Journal of econometrics, 65(1), 83-108.

6. Camarinha-Matos, L. M., and Afsarmanesh, H, (2005), "Collaborative networks: a new scientific discipline", Journal of intelligent manufacturing, 16(4-5), 439-452.

7. Cantù, C., (2010), "Exploring the role of spatial relationships to transform knowledge in a business ideaBeyond a geographic proximity", Industrial Marketing Management, Vol.39 No.6, pp.887-897.

8. Caputo, F., Walletzky, L., and Štepánek, P, (2018), "Towards a systems thinking based view for the governance of a smart city's ecosystem: A bridge to link Smart Technologies and Big Data”, Kybernetes.

9. Carayannis, E. G., and Campbell, D. F, (2010), "Triple helix, quadruple helix and quintuple helix and how do knowledge, innovation and the environment relate to each other?: a proposed framework for a trans-disciplinary analysis of sustainable development and social ecology", International Journal of Social Ecology and Sustainable Development (IJSESD), Vol.1 No.1, pp.41-69.

10. Carlsson, B., Jacobsson, S., Holmén, M., and Rickne, A, (2002), "Innovation systems: analytical and methodological issues", Research Policy, Vol.31 No.2, pp.233-245.

11. Carlsson, B., and Stankiewicz, R., (1991), "On the nature, function, and composition of technological systems", Journal of Evolutionary Economics, Vol.1 No.2, pp.93-118.

12. Chauhan, A., Malviya, O. P., Verma, M., \&Mor, T. S., (2018), "Blockchain and Scalability", In 2018 IEEE International Conference on Software Quality, Reliability and Security Companion (QRS-C) (pp. 122-128), IEEE.

13. Chen, Y., (2017), "Blockchain Tokens and the Potential Democratization of Entrepreneurship and Innovation".

14. Coenen, L., and López, F. J. D., (2010), “Comparing systems approaches to innovation and technological change for sustainable and competitive economies: an explorative study into conceptual commonalities, differences, and complementarities", Journal of Cleaner Production, Vol.18 No.12, pp.1149-1160.

15. Cooke, P., Uranga, M. G., and Etxebarria, G., 1997, "Regional innovation systems: Institutional and organisational dimensions", Research Policy, Vol.26 No.4-5, pp.475-491.

16. Davidson, S., De Filippi, P., and Potts, J., (2016), "Disrupting governance: The new institutional economics of distributed ledger technology".

17. Davidson, S., De Filippi, P., and Potts, J., (2018), "Blockchains and the economic institutions of capitalism", Journal of Institutional Economics, pp.1-20.

18. Diamandis, P. H., and Kotler, S., (2012), “Abundance: The future is better than you think", Simon and Schuster.

19. Dionisio, M., (2019), "The evolution of social entrepreneurship research: a bibliometric analysis", Social Enterprise Journal, 15(1), 22-45.

20. Fisch, C., (2019), "Initial coin offerings (ICOs) to finance new ventures", Journal of Business Venturing, 34(1), 1-22.

21. Funk, E., Riddell, J., Ankel, F., and Cabrera, D., (2018), "Blockchain technology: a data framework to improve validity, trust, and accountability of information exchange in health professions education", Academic Medicine, 93(12), 1791-1794.

22. Huges, E. (1993), "A Cypherpunk's Manifesto", available at https:// www.activism.net/cypherpunk/manifesto.html (accessed 18 May 2018).

23. Gatteschi, V., Lamberti, F., Demartini, C., Pranteda, C., \&Santamaría, V., (2018), "Blockchain and Smart Contracts for Insurance: Is the Technology Mature Enough?”, Future Internet, 10(2), 20.

24. Greenhalgh, T., Robert, G., Macfarlane, F., Bate, P., Kyriakidou, O., and Peacock, R., (2005), "Storylines of research in diffusion of innovation: a meta-narrative approach to systematic review", Social science \& medicine, 61(2), 417-430.

25. Janowicz, K., Regalia, B., Hitzler, P., Mai, G., Delbecque, S., Fröhlich, M., ... \& Lazarus, T. (2018). On the prospects of blockchain and distributed ledger technologies for open science and academic publishing. Semantic Web, (Preprint), 1-11.

26. Ibáñez, L. D., Simperl, E., Gandon, F., and Story, H., (2017), "Redecentralizing the web with distributed ledgers", IEEE Intelligent Systems, Vol.32 No.1, pp.92-95.

27. Keupp, M. M., Palmié, M., and Gassmann, O., (2012), "The strategic management of innovation: A systematic review and paths for future research", International Journal of Management Reviews, 14(4), 367-390.

28. Kewell, B., Adams, R., \& Parry, G., (2017), “Blockchain for good?”, Strategic Change, 26(5), 429-437. 
29. Klein, M., and Sauer, A., (2016), "Celebrating 30 years of innovation system research: What you need to know about innovation systems”, Hohenheim Discussion Papers in Business, Economics, and Social Sciences.

30. Kurzweil, R., (2001), “The Law of Accelerating Returns”, Kurzweil Accelerating Intelligence.

31. Kuzuno, H., and Tziakouris, G., (2018), "Ad-hoc Analytical Framework of Bitcoin Investigations for Law Enforcement”, IEICE TRANSACTIONS on Information and Systems, 101(11), 2644-2657.

32. Larios-Hernández, G. J, (2017), "Blockchain entrepreneurship opportunity in the practices of the unbanked", Business Horizons, 60(6), 865-874.

33. Lazzeretti, L., and Capone, F., (2016), "How proximity matters in innovation networks dynamics along the cluster evolution. A study of the high technology applied to cultural goods", Journal of Business Research, Vol.69 No.12, pp.5855-5865.

34. Leitner, K. H., Warnke, P., \&Rhomberg, W. (2016). New forms of innovation: critical issues for future pathways. Foresight, 18(3), 224-237.

35. Li, Z., Wang, W. M., Liu, G., Liu, L., He, J., and Huang, G. Q., (2018), “Toward open manufacturing: A cross-enterprises knowledge and services exchange framework based on blockchain and edge computing”, Industrial Management \& Data Systems, Vol.118 No.1, pp.303-320.

36. Lipsey, R. G., Carlaw, K. I., and Bekar, C. T., (2005). "Economic transformations: general purpose technologies and long-term economic growth", OUP Oxford.

37. Lundvall, B. A., (1992), National Systems of Innovation: An Analytical Framework, Pinter, London.

38. Mahto, R. V., Belousova, O., \& Ahluwalia, S. (2017). Abundance-A new window on how disruptive innovation occurs. Technological Forecasting and Social Change.

39. Malerba, F. (Ed), (2004), Sectoral systems of innovation: concepts, issues and analyses of six major sectors in Europe, Cambridge University Press, Cambridge.

40. Manski, S., (2017), "Building the blockchain world: Technological commonwealth or just more of the same?", Strategic Change, 26(5), 511-522.

41. Markard, J., Hekkert, M., and Jacobsson, S., (2015), "The technological innovation systems framework: Response to six criticisms", Environmental Innovation and Societal Transitions, Vol.16, pp.76-86.

42. Markard, J., and Truffer, B., (2008), "Technological innovation systems and the multi-level perspective: Towards an integrated framework”, Research Policy, Vol.37 No.4, pp.596-615.

43. Marsal-Llacuna, M. L., (2017), "Future living framework: Is blockchain the next enabling network?", Technological Forecasting and Social Change.

44. May, T.C., (1988), "The Crypto Anarchist Manifesto", available at http://nakamotoinstitute.org/cryptoanarchist-manifesto/\#selection-51.6-87.64 (accessed 28 May 2018).

45. Mendonça, S., Crespo, N., and Simões, N., (2015), "Inequality in the network society: An integrated approach to ICT access, basic skills, and complex capabilities", Telecommunications Policy, 39(3-4), 192-207.

46. Nohria, N., (1994). Networks and organisations: structure, form, and action.

47. North, D. C., (1991), "Institutions”, Journal of Economic Perspectives, Vol.5 No.1, pp.97-112.

48. Norta, A., (2015), "Establishing distributed governance infrastructures for enacting cross-organisation collaborations", In International Conference on Service-Oriented Computing (pp. 24-35). Springer, Berlin, Heidelberg.

49. Nowiński, W., and Kozma, M., (2017), "How Can Blockchain Technology Disrupt the Existing Business Models?”, Entrepreneurial Business and Economics Review, Vol.5 No.3, pp.173-188.

50. Oh, J., and Shong, I., (2017), "A case study on business model innovations using Blockchain: focusing on financial institutions", Asia Pacific Journal of Innovation and Entrepreneurship, Vol.11 No.3, pp.335-344.

51. O'Leary, D. E., (2017), "Configuring blockchain architectures for transaction information in blockchain consortiums: The case of accounting and supply chain systems", Intelligent Systems in Accounting, Finance and Management, 24(4), 138-147.

52. Olnes, S., Ubacht, J., and Janssen, M., (2017), „Blockchain in government: Benefits and implications of distributed ledger technology for information sharing".

53. Ozcan, S., and Islam, N., (2014), "Collaborative networks and technology clusters-the case of nanowire", Technological Forecasting and Social Change, Vol.82, pp.115-131.

54. Pazaitis, A., De Filippi, P., and Kostakis, V., (2017), "Blockchain and value systems in the sharing economy: The illustrative case of Backfeed", Technological Forecasting and Social Change, Vol.125, pp.105-115.

55. Petersen, K., Feldt, R., Mujtaba, S., and Mattsson, M., (2008), Systematic Mapping Studies in Software Engineering, In EASE (Vol. 8, pp. 68-77).

56. Potts, J. (2018). Governing the innovation commons. Journal of Institutional Economics, 14(6), 10251047.

57. Prahalad, C. K. (2012). Bottom of the Pyramid as a Source of Breakthrough Innovations. Journal of Product Innovation Management, 29(1), 6-12. 
58. Rosling, H., Rönnlund, A. R., \&Rosling, O. (2018). Factfulness: Ten Reasons We're Wrong about the World--and why Things are Better Than You Think. Flatiron Books.

59. Scott, B., Loonam, J., and Kumar, V., (2017), "Exploring the rise of blockchain technology: Towards distributed collaborative organisations", Strategic Change, Vol.26 No.5, pp.423-428.

60. Seidel, M. D. L., (2018), "Questioning Centralised Organisations in a Time of Distributed Trust”, Journal of Management Inquiry, Vol.27 No.1, pp.40-44.

61. Sharples, M., and Domingue, J., (2016), "The blockchain and kudos: A distributed system for educational record, reputation and reward", In European Conference on Technology Enhanced Learning (pp. 490496). Springer, Cham.

62. Shermin, V., (2017), "Disrupting governance with blockchains and smart contracts", Strategic Change, 26(5), 499-509.

63. Sutherland, W. J., Barnard, P., Broad, S., Clout, M., Connor, B., Côté, I. M., ... \& Fox, M., (2017), “A 2017 horizon scan of emerging issues for global conservation and biological diversity", Trends in Ecology \& Evolution, 32(1), 31-40.

64. Swan, M., (2015), Blockchain: Blueprint for a new economy, O'Reilly Media, Inc, Sebastopol.

65. Swan, M., (2017), "Anticipating the Economic Benefits of Blockchain", Technology Innovation Management Review, Vol.7 No.10, pp.6-13.

66. Swan, M., (2016), "Blockchain temporality: smart contract time specifiability with blocktime", In International symposium on rules and rule markup languages for the semantic web, 184-196. Springer, Cham.

67. Tapscott, D., and Tapscott, A., (2016), Blockchain revolution: how the technology behind bitcoin is changing money, business, and the world, Penguin.

68. Tapscott, D., and Tapscott, A., (2017a), "How blockchain will change organisations", MIT Sloan Management Review, Vol.58 No.2, pp.10.

69. Tapscott, D., and Tapscott, A., (2017b), "The BlockChain revolution and higher education", Educause Review, Vol.52 No.2, pp.11-24.

70. Tapscott, A., and Tapscott, D., (2017c), How blockchain is changing finance, Harvard Business Review, Vol.1.

71. Till, B. M., Peters, A. W., Afshar, S., and Meara, J. G. (2017). From blockchain technology to global health equity: can cryptocurrencies finance universal health coverage?. BMJ global health, 2(4), e000570.

72. Van Valkenburgh, P., Dietz, J., De Filippi, P., Shadab, H., Xethalis, G., and Bollier, D., (2015), Distributed collaborative organisations: Distributed networks \& regulatory frameworks.

73. Veuger, J., (2018), "Trust in a viable real estate economy with disruption and Blockchain", Facilities, 36(1/2), 103-120.

74. Von Hippel, E., (1976), "The dominant role of users in the scientific instrument innovation process", Research Policy, 5(3), 212-239.

75. Warnke, P., Koschatzky, K., Dönitz, E., Zenker, A., Stahlecker, T., Som, O., ... \&Güth, S., (2016), Opening up the innovation system framework towards new actors and institutions (No. 49), Fraunhofer ISI Discussion Papers Innovation Systems and Policy Analysis.

76. Wolf, T., Griffioen, J., Calvert, K. L., Dutta, R., Rouskas, G. N., Baldin, I., and Nagurney, A., (2014), "ChoiceNet: toward an economy plane for the Internet", ACM SIGCOMM Computer Communication Review, Vol.44 No.3, pp.58-65.

77. Wolfond, G. (2017). A Blockchain Ecosystem for Digital Identity: Improving Service Delivery in Canada's Public and Private Sectors. Technology Innovation Management Review, 7(10).

78. Yermack, D., (2017), “Corporate governance and blockchains”, Review of Finance, Vol.21 No.1, pp.731.

79. Ying, W., Jia, S., and Du, W. (2018). Digital enablement of blockchain: Evidence from HNA group. International Journal of Information Management, 39, 1-4.

80. Yli-Huumo, Ko, J., D., Choi, S., Park, S., and Smolander, K., (2016). "Where is current research on blockchain technology? - a systematic review.”, PloS one, 11(10) 